\title{
A study on the effects of service quality on brand personality: Evidence from Hotel industry
}

\author{
Emeliya Ghorbani Siavoshani $^{\mathrm{a}}$, Hamed Dehghanan ${ }^{\mathrm{b}}$ and Ghasem Bakhshandeh ${ }^{\mathrm{b}}$
}

${ }^{a}$ Masters of Business Administration, Alborz Institute of Higher Education, Qazvin, Iran

${ }^{b}$ Department of Management and Accounting, Allame Tabatabaei University, Tehran, Iran

\section{H R O N I C L E}

Article history:

Received January 4, 2014

Accepted 28 May 2014

Available online

June 12014

Keywords:

Service quality

Brand personality

SERVQUAL

\section{Introduction}

Brand personality has been one of the most popular topics for several decades and most advertising practitioners as well as several marketing academics have accepted it. For Years, many have argued that brand personality could be an important topic of study because it may give us insight to differentiate brands, develop the emotional characteristics of a brand and augment the personal concept of a brand for the consumer. Nevertheless, despite the fact that brand personality has attracted considerable academic attention, it has been also criticized on a number of its components (Aaker \& Fournier, 1995). For one, at the conceptual level, there is some confusion over the precise definition of brand personality and how it is distinguished from brand image. Aaker et al. (2001) argued that the meaning embedded in consumption symbols, such as commercial brands, could serve to represent and institutionalize the assets. They conducted four studies to investigate how symbolic and expressive attributes associated with commercial brands were structured and how this structure varied across 3 cultures depending on a combined technique. They discussed the meaning of the

*Corresponding author

E-mail addresses: G.bakhshandeh@gmail.com (G. Bakhshandeh)

C 2014 Growing Science Ltd. All rights reserved.

doi: 10.5267/j.msl.2014.6.004 
brand personality dimensions in the context of cross-cultural research on values and affect, globalization issues, and cultural frame shifting. Arasli et al. (2005) presented an empirical investigation to measure the service quality perceptions of Greek Cypriot bank customers. They also tested the relationship between service quality, customer satisfaction and positive word of mouth (WOM), in the light of changing bank market dynamics due to EU accession. Using SERVQUAL technique, the study has disclosed that bank customers did not receive their expectations where the largest gap was achieved in the responsiveness-empathy dimension. In their survey, reliability items maintained the highest impact on customer satisfaction, which in turn kept a statistically significant effect on the positive WOM.

Bosnjak et al. (2007) identified and operationalized indigenous German brand personality attributions from a person-centric perspective. The study entailed an exploration of those positive as well as negative human personality dimensions applicable to brands and identified four dimensions of brand personality including Drive, Conscientiousness, Emotion, and Superficiality. Hussey and Duncombe (1999) described the development of a set of implicit characteristics for two animation sets to which respondents would respond similarly and with consistency to identify the brand image and consequently to detect the motivations behind brand choice. Parasuraman et al. (2005) conceptualized, constructed, refined, and examined a multiple-item scale (E-S-QUAL) for measuring the service quality distributed by Web sites on which customers shop online. In their survey, a twostage empirical data collection disclosed that two various scales were essential for capturing electronic service quality. Personality also influences on building a brand. Plummer (1985) discussed how personality could make a difference on building a brand. Karoubi (2014) Aaker's five-dimension model for measuring brand personality of a state-owned airline company and a private one. The results of the data analysis indicated that Mahan Airline was superior to Iran Air in all the five dimensions.

\section{The proposed study}

This paper presents an empirical investigation to study the effects of service quality on brand personality in hotel industry. The study uses two questionnaires, one for measuring brand personality by using Aaker's questionnaire (Aaker, 1997) and the other one is adopted from Parasuraman's work (Parasuraman et al., 1985, 2005). The study has accomplished among regular customers of a hotel in city of Mashad, Iran. The sample size is calculated as follows,

$$
N=Z_{\alpha / 2}^{2} \frac{p \times q}{e^{2}},
$$

where $N$ is the sample size, $p=1-q$ represents the probability, $z_{\alpha / 2}$ is CDF of normal distribution and finally $\varepsilon$ is the error term. For our study we assume $p=0.5, z_{\alpha / 2}=1.96$ and $e=0.05$, the number of sample size is calculated as $N=384$. Fig. 1 demonstrates the summary of the proposed study.

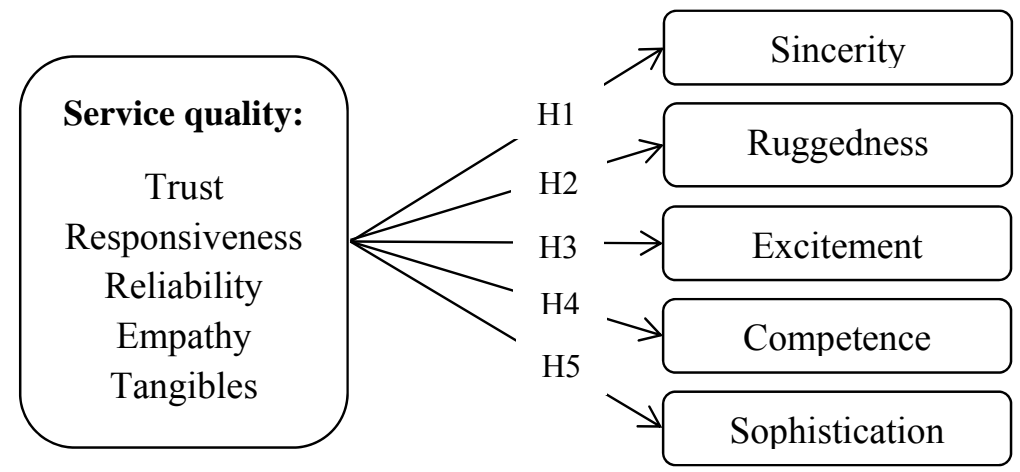

Fig. 1. The proposed study 
Based on the structure of Fig. 1, the following five hypotheses are proposed.

1. Quality of services influences positively on brand sincerity.

2. Quality of services influences positively on brand ruggedness.

3. Quality of services influences positively on brand excitement.

4. Quality of services influences positively on competence.

5. Quality of services influences positively on sophistication.

The study uses structural equation modeling to examine different hypotheses of the survey. Table 1 shows some basic statistics associated with the proposed study.

\section{Table 1}

The results of statistical observations

\begin{tabular}{lcc}
\hline Criterion & The results & Desirable value \\
\hline Chi-Square/df & 2.87 & $<3.0$ \\
Goodness of fit index (GFI) & 0.902 & $>0.90$ \\
Root Mean Square Estimated (RMSEA) & 0.0063 & $<0.1$ \\
Certified Factor Index (CFI) & 0.911 & $>0.90$ \\
Normalized Factor index (NFI) & 0.905 & $>0.90$ \\
NNFI & 0.960 & $>0.90$ \\
\hline
\end{tabular}

As we can see from the results of Table 1, all statistical observations were well above the acceptable limit and we therefore can examine the hypotheses based on the results of SEM implementation.

\section{The results}

In this section, we present details of our findings on testing various hypotheses based on SEM implementation shown in Table 2 and the results of our findings confirms all hypotheses of the survey.

Table 2

The summary of standard coefficients

\begin{tabular}{ccccc}
\hline Hypothesis & $\beta$ & t-value & Sig. & Result \\
\hline First & 0.168 & 5.92 & 0.000 & Confirmed \\
Second & 0.149 & 7.83 & 0.000 & Confirmed \\
Third & 0.247 & 6.92 & 0.000 & Confirmed \\
Fourth & 0.361 & 8.77 & 0.000 & Confirmed \\
Fifth & 0.152 & 8.85 & 0.000 & Confirmed \\
\hline
\end{tabular}

\section{Conclusion}

We have presented an empirical investigation to study the effects of service quality on brand personality in hotel industry. Using structural equation modeling, the study has determine a positive and meaningful relationships between five factors including Sincerity, Excitement, Competence, Sophistication, as well as Ruggedness and service quality. The results of our investigation are consistent with Karoubi (2014), Matzler et al. (2006), Venable et al. (2005) and Muhammadian et al. (2009).

\section{Acknowledgement}

The authors would like to thank the officials of Sard Hotel for cordially cooperating in accomplishment of the survey. 


\section{References}

Aaker, J., \& Fournier, S. (1995). A brand as a character, a partner and a person: three perspectives on the question of brand personality. Advances in Consumer Research, 22, 391-391.

Aaker, J. L. (1997). Dimensions of brand personality. Journal of Marketing research, 34(3), 347-356.

Aaker, J. L., Benet-Martinez, V., \& Garolera, J. (2001). Consumption symbols as carriers of culture: A study of Japanese and Spanish brand personality constucts. Journal of personality and social psychology, 81(3), 492-508.

Arasli, H., Mehtap-Smadi, S., \& Katircioglu, S. T. (2005). Customer service quality in the Greek Cypriot banking industry. Managing Service Quality, 15(1), 41-56.

Bosnjak, M., Bochmann, V., \& Hufschmidt, T. (2007). Dimensions of brand personality attributions: A person-centric approach in the German cultural context. Social Behavior and Personality: an international journal, 35(3), 303-316.

Karoubi, M. (2014). Investigating brand personality of state-owned and private airlines: Maham Versus Iran Air. Management Science Letters, 4(6), 1245-1254.

Matzler, K., Bidmon, S., \& Krauter, S. G. (2006). Individual determinants of brand affect: the role of the personality traits of extraversion and openness to experience. Journal of Product \& Brand Management, 15 (7), 427-434.

Muhammadian, M., Farahmand, S., \& Yousefi Dastjerdi, M. (2009). Evaluating the position of Toshiba brand personality in comparison with four similar global brands in Iran's market using Aaker's five-dimension model. Journal of Marketing Management, 2(4), 129-144.

Hussey, M., \& Duncombe, N. (1999). Projecting the right image: using projective techniques to measure brand image. Qualitative Market Research: An International Journal, 2(1), 22-30.

Parasuraman, A., Zeithaml, V. A., \& Berry, L. L. (1988). Servqual. Journal of retailing, 64(1), 12-37.

Parasuraman, A., Zeithaml, V. A., \& Malhotra, A. (2005). ES-QUAL a multiple-item scale for assessing electronic service quality. Journal of service research, 7(3), 213-233.

Plummer, J. T. (1985). How personality makes a difference. Journal of Advertising Research, 24(6), 27-31.

Venable, B. T., Rose, G. M., Bush, V. D., \& Gilbert, F. W. (2005). The role of brand personality in charitable giving: An assessment and validation. Journal of the Academy of Marketing Science, 33 (3), 295-312. 